\title{
Snakebites as a largely neglected problem in the Brazilian Amazon: highlights of the epidemiological trends in the State of Amazonas
}

\author{
Esaú Samuel Feitosa ${ }^{[1]}$, Vanderson Sampaio ${ }^{[2]}$, Jaqueline Sachett ${ }^{[1]}$, \\ Daniel Barros de Castro ${ }^{[2]}$, Maria das Dores Nogueira Noronha ${ }^{[3]}$, \\ Jorge Luis López Lozano ${ }^{[3]}$, Emiro Muniz ${ }^{[3]}$, Luiz Carlos de Lima Ferreira ${ }^{[1],[3]}$, \\ Marcus Vinícius Guimarães de Lacerda ${ }^{[1],[3]}$ and Wuelton Marcelo Monteiro[ ${ }^{[1],[3]}$
}

[1]. Programa de Pós-Graduação em Medicina Tropical, Escola de Ciências da Saúde, Universidade do Estado do Amazonas, Manaus, AM. [2]. Fundação de Vigilância em Saúde, Manaus, AM. [3]. Fundação de Medicina Tropical Doutor Heitor Vieira Dourado, Manaus, AM.

\begin{abstract}
Envenoming snakebites are thought to be a particularly important threat to public health worldwide, especially in rural areas of tropical and subtropical countries. The true magnitude of the public health threat posed by snakebites is unknown, making it difficult for public health officials to optimize prevention and treatment. The objective of this work was to conduct a systematic review of the literature to gather data on snakebite epidemiology in the Amazon region and describe a case series of snakebites from epidemiological surveillance in the State of Amazonas (1974-2012). Only 11 articles regarding snakebites were found. In the State of Amazonas, information regarding incidents involving snakes is scarce. Historical trends show an increasing number of cases after the second half of the 1980s. Snakebites predominated among adults (20-39 years old; 38\%), in the male gender $(78.9 \%)$ and in those living in rural areas $(85.6 \%)$. The predominant snake envenomation type was bothropic. The incidence reported by the epidemiological surveillance in the State of Amazonas, reaching up to 200 cases/100,000 inhabitants in some areas, is among the highest annual snakebite incidence rates of any region in the world. The majority of the cases were reported in the rainy season with a case-fatality rate of $0.6 \%$. Snakebite envenomation is a great disease burden in the State of Amazonas, representing a challenge for future investigations, including approaches to estimating incidence under-notification and casefatality rates as well as the factors related to severity and disabilities.
\end{abstract}

Keywords: Snakebite. Epidemiology. Epidemiological surveillance. Neglected disease. Amazon.

\section{EPIDEMIOLOGIC CONTEXT OF SNAKEBITES WORLDWIDE AND IN BRAZIL}

A snakebite is an injury caused by a bite from a snake, often resulting in puncture wounds inflicted by the animal's fangs and in some cases resulting in envenomation. Although snakebites occur worldwide, envenoming snakebites are thought to pose a particularly important yet largely neglected threat to public health in rural areas of tropical and subtropical countries. The true magnitude of the public-health threat posed by snakebites in these countries is unknown, which makes it difficult for public health officials to optimize prevention and treatment ${ }^{(1)(2)(3)(4)}$.

Globally, at least 421,000 cases of envenomation and 20,000 deaths occur each year due to snakebites, and the true figures may be as high as $1,841,000$ cases and 94,000 deaths.

\footnotetext{
Corresponding author: Prof. Wuelton Marcelo Monteiro. FMT-HVD. Av. Pedro Teixeira 25, Bairro Dom Pedro, 69040-000 Manaus, AM, Brasil.

Phone: 5592 2127-3555

e-mail:wueltonmm@ibest.com.br

Received 20 May 2013

Accepted 22 May 2014
}

Based on the fact that one in every four snakebites causes envenomation, between 1.2 million and 5.5 million snakebites may occur annually ${ }^{(4)}$. In Brazil, health providers were required to notify authorities of envenomations beginning in 1986. The importance of envenoming snakebites is revealed by the high number of reported cases in the Brazilian Information System of Notifiable Diseases [Sistema Nacional de Agravos de Notificação (SINAN)]. The under-reporting of these incidents is a serious problem, as they have previously only been reported in poisoning control centers. The objectives of snakebite epidemiological surveillance are to reduce the incidence of this type of incident by promoting health education and to reduce its severity, frequency of sequelae and lethality through the appropriate use of serum therapy ${ }^{(5)}$. In Brazil, SINAN has reported a considerable increase in the number of reported snakebites since 2001. In 2008, 26,156 incidents were recorded in the country, corresponding to an incidence of 13.8 cases per 100,000 inhabitants. However, there is a significant variation among regions, with the highest incidence occurring in the North Region ${ }^{(5)}$.

Snakebite outcomes depend on numerous factors, including the species, the area of the body bitten, the amount of venom injected, and the health conditions of the person bitten. Most 
snakebites, whether by a venomous snake or not, will have some type of local effect. Bites may be extremely painful, with the local tissue in some cases becoming severely swollen within five minutes. This area may also bleed and blister and can eventually experience tissue necrosis. Other common initial symptoms include lethargy, bleeding, weakness, nausea, and vomiting. Depending on the snake genus, symptoms may become more life-threatening over time, developing into hypotension, tachypnea, severe tachycardia, severe internal bleeding, altered sensorium, kidney failure, and respiratory failure ${ }^{(5)}()^{6}$. In Brazil, envenoming snakes are represented by the genera Bothrops (known as jararaca, jararacuçu, urutu, caiçaca, comboia), Crotalus (cascavel), Lachesis (surucucupico-de-jaca) and Micrurus (true coral) ${ }^{(5)}$. Bites from nonvenomous snakes can also cause injury, often due to lacerations caused by the snake's teeth or from a resulting infection ${ }^{(5)(6)}$.

\section{SNAKEBITE EPIDEMIOLOGY IN THE BRAZILIAN AMAZON: A SYSTEMATIC REVIEW}

A systematic review was conducted to identify relevant information regarding the snakebite epidemiology in the Brazilian Amazon, using the concept of the Legal Amazon, which comprises the States of the North Region, Mato Grosso and Maranhão. The sources of published data on snakebites in the Brazilian Amazon were MEDLINE (Medical Literature Analysis and Retrieval System Online) (1948 to March 2013) and LILACS (Literatura Latino-Americana) (1982 to March 2013). The following search strategy was employed for both databases: (Snakebite OR Snake bite OR Ophidism OR Ophidia).mp AND (Amapá OR Amazonas OR Acre OR Rondonia OR Roraima OR Tocantins OR Pará OR Maranhão OR Mato Grosso).mp. Studies were also searched in the Journal Acta Amazonica (published by the Instituto Nacional de Pesquisas da Amazônia, Manaus, State of Amazonas) from 1971 to 2013 (April-June issue) and directly on the journal website (http://acta.inpa.gov.br/home.php?opcao=fasciculos). Acta Amazonica is the most traditional scientific journal published by an Amazonian institution. All study design types with primary data were included. The abstracts were analyzed in detail by two independent reviewers, and publications were selected if they provided any type of epidemiological information in at least one patient with a diagnosis of snakebite. Disagreement between the two reviewers was solved through consensus. From the included studies, data were extracted on the publication date, study design, origin of data (epidemiological surveillance or medical records), number of patients, seasonality, snake species/incident type, anatomical region affected, time until medical care, participant characteristics (e.g., gender, age range, occupation, and rural/urban residence) and case fatality. Studies were excluded if they did not have snakebites as the target condition and if they focused solely on biochemical and pharmacological venom assays, snake biology, physiology and ecology and on results obtained outside of the Amazon. Results from intervention studies were also excluded. Potentially relevant papers in all languages were accessed to review the full text. The references and reviews cited by each relevant paper were scrutinized to locate additional papers.
Through abstract analysis, 73 articles were retrieved, and after application of the inclusion and exclusion criteria, 11 articles $^{(7)(8)(9)(10)(11)(12)(13)(14)(15)(16)(17)}$ were selected (Figure 1). These studies were published from 1996 to 2012, and they included six case series (five based on epidemiological surveillance and one on hospital medical records), two questionnaire-based community surveys and three case reports. The case series studies were carried out in the State of Acre (one from Cruzeiro do Sul with 195 cases $^{(17)}$ and one from Rio Branco with 140 cases $\left.^{(11)}\right)$, Amapá (909 cases throughout the state) ${ }^{(12)}$, Amazonas (1,576 cases from 34 municipalities) ${ }^{(9)}$, Mato Grosso (307 cases from Cuiabá) ${ }^{(8)}$ and Roraima (309 cases from eight municipalities) ${ }^{(10)}$. The community surveys were conducted with forest-dwelling Indians and rubber tappers (seringueiros) in the Juruá Valley, Acre ${ }^{(7)}$, and with inhabitants of 10 riverine communities in the municipality of Berry, Amazonas. The case reports were all from the State of Pará(13) (15) (16).

Six studies presented data by sex and showed that snakebites predominated in men, with rates ranging from $75.6 \%{ }^{(10)}$ to $82.1 \%{ }^{(14)}$. Although the age group classifications were not the same, in all of the studies presenting this information, snakebites occurred primarily in adults ${ }^{(8)(9)(10)(17)}$, which strongly suggests an occupational risk. People living in rural areas ${ }^{(8)(9)(11)(12)(17)}$ and/or workers engaged in farming, hunting and forestry activities $^{(7)(14)}$ were the most affected.

In the State of Amazonas, seasonality was tested in 13 municipalities and cases occurred mostly in March, April and July ${ }^{(9)}$. In Roraima, the snakebite incidence was higher from March to July ${ }^{(10)}$. In Cruzeiro do Sul, snakebite cases occurred more often from November to April, which correlated with the higher rainfall period ${ }^{(17)}$.

Bothropic accidents were the most commonly recorded in Acre (75.7\% in Rio Branco), Amapá (67.5\%), Amazonas (48.6\%), Mato Grosso (99\%) and Roraima (81.8\%). Lachetic accidents predominated in the case series from Cruzeiro do Sul (Acre) $(51.3 \%)$, followed by bothropic snakebites (Bothrops and Bothriopsis) (38\%). However, these authors highlight a possible confounding factor regarding snake identification by the population living in the study area ${ }^{(17)}$. Incidents involving non-venomous snakes were mostly recorded in Mato Grosso $(56 \%)$. All of the studies showed that the lower limbs were the most affected anatomical region. The time elapsed from the bite to attending the patient was typically longer than $6 \mathrm{~h}^{(9)(12)}$. The case fatality rate was $0.5 \%$ in Cruzeiro do Sul ${ }^{(17)}$, $1 \%$ in Amazonas ${ }^{(9)}, 400$ deaths $/ 100,000$ per lifetime in the Juruá Valley ${ }^{(7)}, 3.6 \%$ per lifetime in the riverine population of Beruri $^{(14)}$ and $3.9 \%$ in Roraima ${ }^{(10)}$.

Three case reports from the State of Pará were included. The first reported case of an incident involving Bothriopsis taeniata in Brazil was described in a 43-year-old man who presented with local edema with hemorrhaging at the bite site and pain, although without coagulopathy ${ }^{(13)}$. The second publication reports a case of hemorrhagic stroke due to bothropic envenomation associated with severe hypertension ${ }^{(15)}$. Two cases of proven coral snake bites were reported in Belém. The first was a severe acute respiratory failure case caused by 
The potentially relevant studies that were identified and screened for retrieval (65 from PubMed and 8 from LILACS)
Studies excluded from PubMed search $(n=56)$ : 12 did not have snakebites as the target condition; 22 focused on biochemical and pharmacological venom assays; 12 focused on snake biology, physiology and ecology; 8 focused on results obtained outside of the Amazon; and 2 reported results from interventional studies

Studies excluded from LILACS $(n=7): 4$ did not have snakebites as the target condition; 2 focused on snake biology, physiology and ecology; and 1 focused on results obtained outside of the Amazon

Studies retrieved for more detailed evaluations (9 from PubMed and 1 from LILACS)
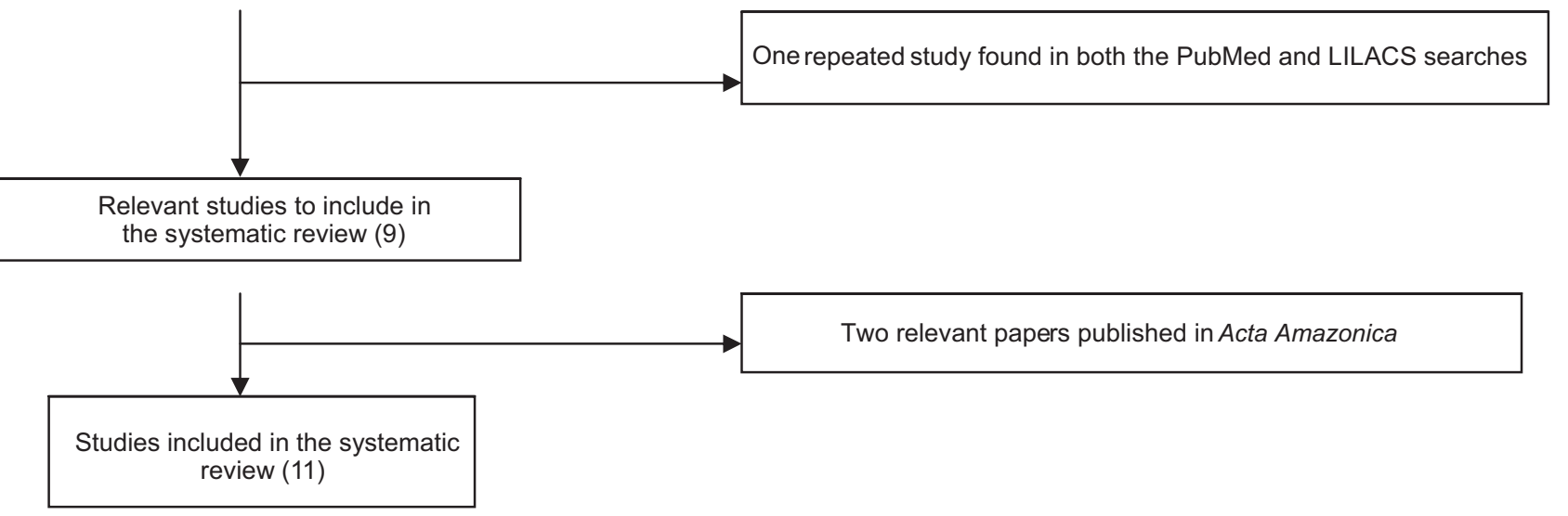

MEDLINE: Medical Literature Analysis and Retrieval System Online. LILACS: Literatura Latino-Americana.

FIGURE 1 - Flowchart for the inclusion of studies on snakebites in the Brazilian Amazon.

Micrurus surinamensis. The second case showed only mild signs of envenomation caused by Micrurus filiformis. Both patients received specific Micrurus anti-venom and were discharged without further complications ${ }^{(16)}$.

\section{SNAKEBITE INCIDENCE IN THE STATE OF AMAZONAS: A HISTORICAL PERSPECTIVE}

The earliest systematic records of snakebites in the State of Amazonas are from 1970, after the establishment of the IMTM (Instituto de Medicina Tropical de Manaus) by Heitor Dourado and Carlos Borborema, an institution that originated the current FMT-HVD (Fundação de Medicina Tropical Doutor Heitor Vieira Dourado). This specialized health service went on to serve as a reference for tropical diseases, including incidents involving poisonous animals. In the second half of the decade, in Manaus, the researcher Paulo Burnheim, with key support from Heitor Dourado (the IMTM director at the time), organized the Centre for Poisonous Animals. The Butantan Institute,
Vital Brazil Institute and Ezequiel Dias Foundation are the antivenoms in Brazil. Beginning in 1986, the Ministry of Health took full responsibility for acquiring the whole production of anti-venoms in this country, thus distributing to the states, which are responsible for transferring it to the municipalities. The Centre for Poisonous Animals began operations in 1985 and is responsible for distributing anti-venom in the State of Amazonas.

From 1974 to 1984,514 snakebite victims were hospitalized in IMTM $^{(18)}$. Figure 2 shows the series of recorded snakebite cases from 1974 to 2012 . The increasing case number pattern is notable after the second half of 1980s. Immediately after the activities of the Centre for Poisonous Animals began operation, it began recording information regarding the total attendance. Thus, the pattern of increasing snakebite cases is the result of a change in institutional protocols, which have led to an improvement of the epidemiological surveillance system for the State of Amazonas. Moreover, with the establishment of 


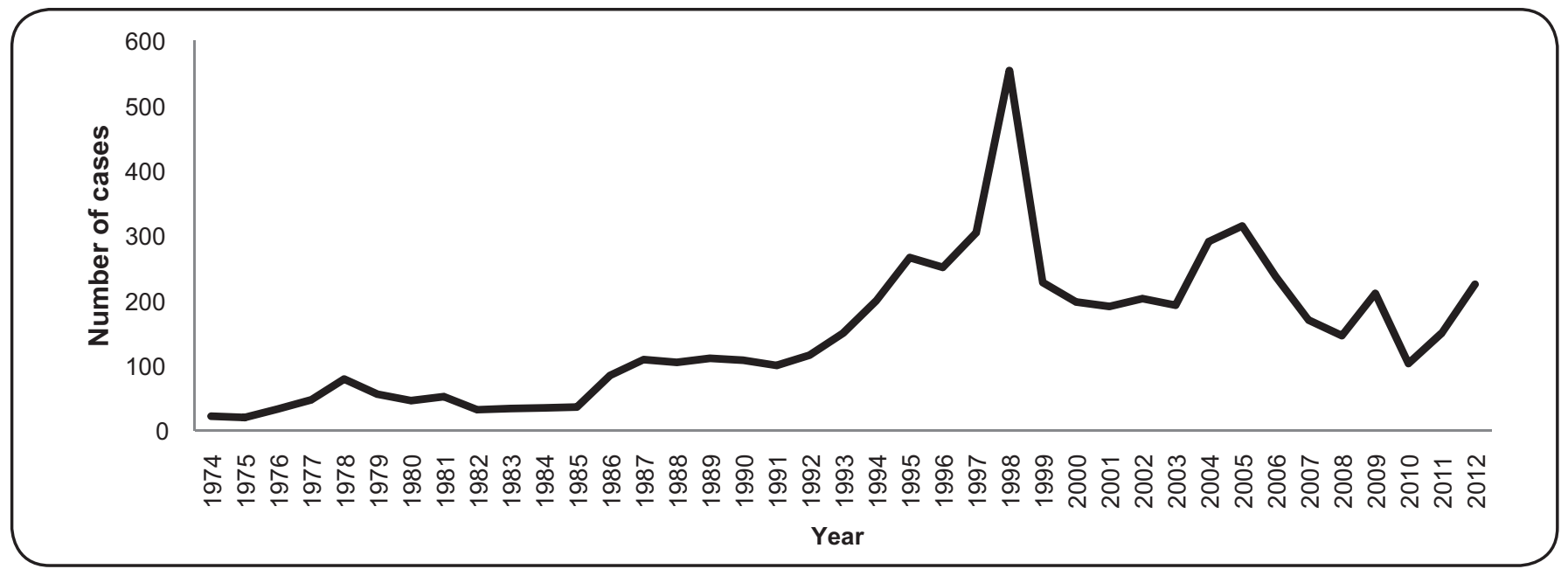

FIGURE 2 - Historical evolution of the number of snakebites recorded from the Fundação de Medicina Tropical Doutor Heitor Vieira Dourado, Manaus (1974-2012).

this specialized service, the state has achieved an optimized distribution of anti-venoms and generates more reliable epidemiological information on snakebites. The first analyses of the demographic characteristics of snakebite victims, the seasonality of cases and the species of snakes involved were conducted during this period ${ }^{(18)(19)}$. These events coincided with a crisis in the anti-venom production system in Brazil in 1986, which culminated with the death of a child in Brasília and caused the government to create the National Programme of Snakebites in the former National Secretariat of Basic Health Activities. During this period, snakebite notifications became compulsory in Brazil, and in 1988, the program was renamed the National Programme for Control of Venomous Animals.

Figure 2 also shows an increasing incidence of snakebites in the 1990s, which peaked in 1998 with 554 cases in IMTM. Since the beginning, the epidemiological surveillance of snakebites in the State of Amazonas has shown that rural activities are closely associated with the occurrence of this problem. In the 1990s, the development of sustainable forestry, fishing and farming in the State of Amazonas was stimulated as a result of the official support of the State government for creating the Zona Franca Verde Program. Given the occupational risk of snakebites, which is related to rural and forest activities, this increased activity likely contributed to the increase in the number of cases. The increase in snakebite occurrences was also related to the intense urbanization of Manaus toward peripheral areas during this decade. This urbanization resulted in an influx of migrants and increased human activity in rural areas, which resulted in an ecological imbalance and increased contact with snakes. In subsequent years, snakebites decreased but have remained a persistent problem to the present day, with a slight increasing trend after 2010. However, the full impact of these environmental changes on snakebite incidence must be further evaluated. It is noteworthy that snakebites are among the leading causes of hospitalization in FMT-HVD.

\section{RECENT EPIDEMIOLOGICAL SURVEILLANCE SHOWS A MAJOR AND PERSISTENT HEALTH PROBLEM IN THE STATE OF AMAZONAS}

From 2007 to 2012, a total of 9,174 snakebite cases were recorded in the State of Amazonas. Figure 3 shows that the cases were distributed in all 62 municipalities of the state, with the highest incidence rates occurring in Anamã, Novo Airão, Rio Preto da Eva, Borba, Alvarães, São Gabriel da Cachoeira, Japurá and Uarini. Over these six years, there was little variation in the annual snakebite incidence, with the largest numbers reported in 2009 (1,969 cases) and the fewest in $2011(1,435)$. During this period, the mean annual incidence in the state was estimated at 45.1 cases $/ 100,000$ inhabitants (the minimum was 6.7 in Manaus, and the maximum was 235.8 in Uarini per 100,000). The high number of snakebites recorded during this period demonstrates the high burden of this health issue for the region. A previous survey from Cruzeiro do Sul found an incidence of 126.62 cases/100,000 inhabitants per year during the 2007-2009 period $^{(17)}$. A systematic review of the global snakebite ${ }^{(4)}$ burden showed that the most affected areas were Southeast Asia, which had a maximum estimated incidence of 84.65 cases/100,000 inhabitants, and the central portion of Sub-Saharan Africa, which had a maximum value of 53.37 cases $/ 100,000$ inhabitants. In the same study, the tropical portion of Latin America had a maximum incidence of 16.12 cases/100,000 inhabitants. The value reported by the epidemiological surveillance in the State of Amazonas reveals this area as having one of the highest incidences of snakebites in the world.

The case series presented here clearly shows a seasonal pattern. Most of the incidents that occurred during the period from December to June were in parallel with the rainy season in the region, with a peak number of cases in March. The months with the lowest case numbers were September and October (Figure 4). The snakebite incidence in the Amazon is under the influence of precipitation, likely because snakes 


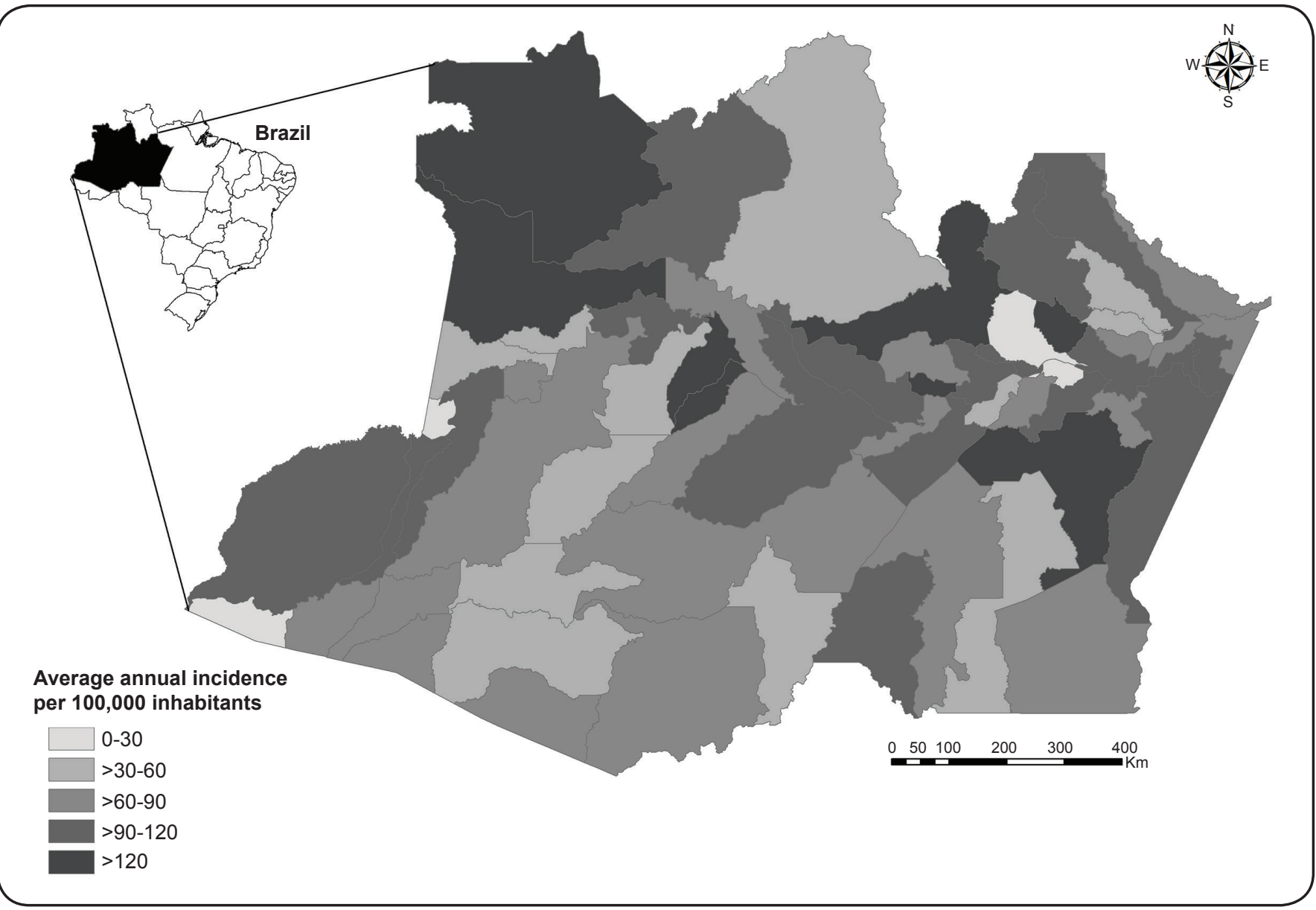

FIGURE 3 - Mean annual snakebite incidence by municipality in the State of Amazonas from 2007 to 2012.

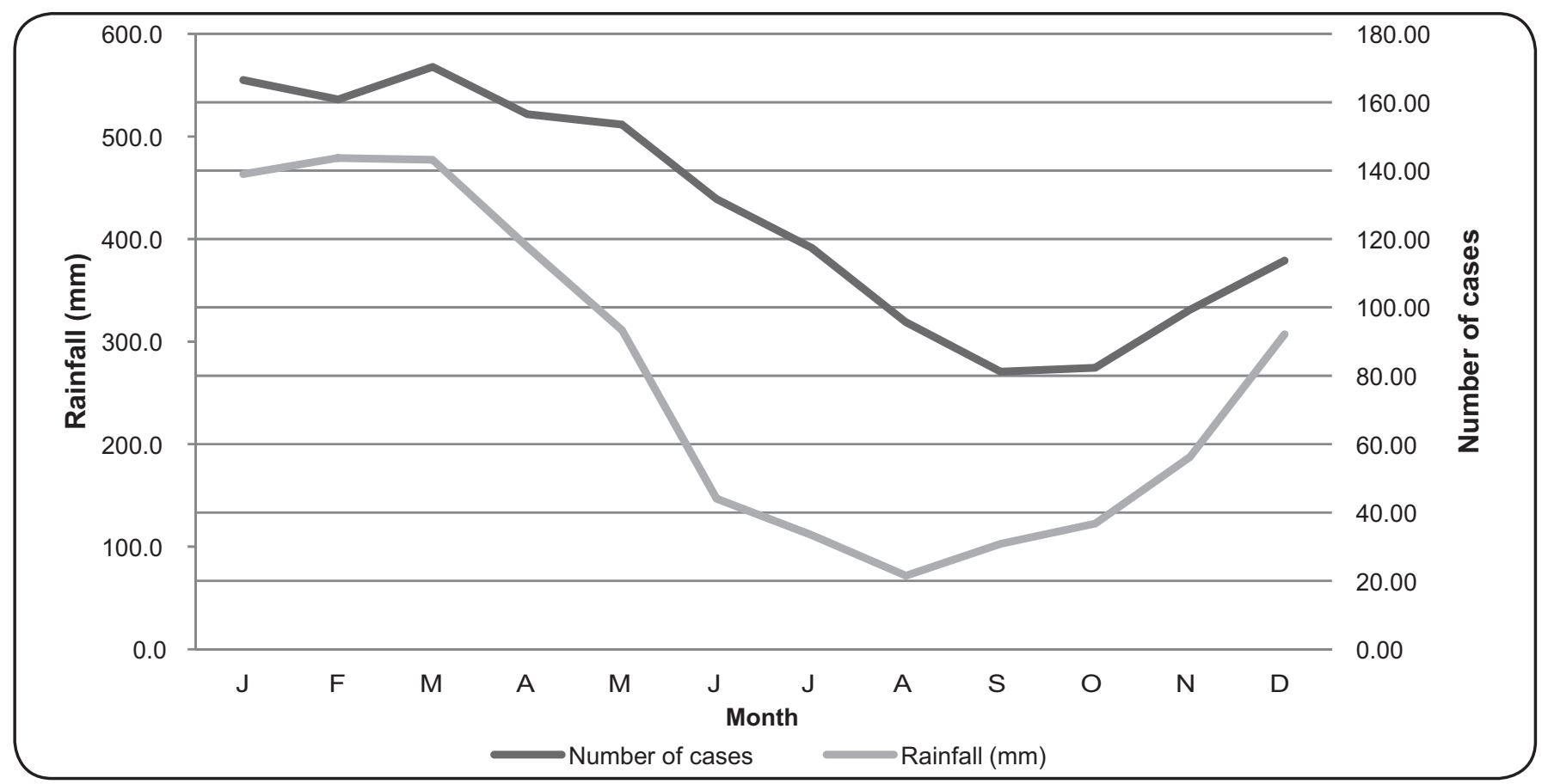

FIGURE 4 - Seasonality (mean monthly number of bites and rainfall) of the snakebites recorded in the State of Amazonas from 2007 to 2012. 
TABLE 1 - Characteristics of the 9,174 snakebite cases recorded from the State of Amazonas (2007-2012).

\begin{tabular}{|c|c|c|}
\hline Characteristics & Number & Frequency $(\%)$ \\
\hline \multicolumn{3}{|l|}{ Gender } \\
\hline male & 7,242 & 78.9 \\
\hline female & 1,931 & 21.1 \\
\hline not available & 1 & 0.1 \\
\hline \multicolumn{3}{|c|}{ Area of occurrence } \\
\hline rural & 7,851 & 85.6 \\
\hline urban & 1,117 & 12.2 \\
\hline periurban & 101 & 1.1 \\
\hline not available & 45 & 0.5 \\
\hline \multicolumn{3}{|l|}{ Age groups } \\
\hline $0-9$ & 396 & 4.3 \\
\hline $10-19$ & 1,647 & 17.9 \\
\hline $20-49$ & 4,736 & 51.8 \\
\hline $50-69$ & 1,534 & 16.7 \\
\hline$>70$ & 248 & 2.7 \\
\hline not available & 613 & 6.7 \\
\hline \multicolumn{3}{|c|}{ Anatomical region affected } \\
\hline head & 92 & 1.0 \\
\hline upper limbs & 1,123 & 12.2 \\
\hline body & 37 & 0,4 \\
\hline lower limbs & 7,853 & 85.6 \\
\hline not available & 69 & 0.8 \\
\hline
\end{tabular}

Time elapsed from bite until care (hours)

$\begin{array}{lcc}0-1 & 1,299 & 14.1 \\ 1-3 & 2,355 & 25.7 \\ 3-6 & 2,229 & 24.3 \\ 6-12 & 1,179 & 12.9 \\ 12-24 & 792 & 8.6 \\ >24 & 743 & 8.1 \\ \text { not available } & 577 & 6.3\end{array}$

\begin{tabular}{lcc}
\hline Type of snakebite & & \\
bothropic & 6,175 & 67.3 \\
lachetic & 1,996 & 21.8 \\
crotalic & 37 & 0.4 \\
elapidic & 36 & 0.4 \\
non-envenoming snakes & 109 & 1.2 \\
not available & 821 & 8.9 \\
\hline Evolution & & \\
discharge & 8,547 & 93.2 \\
death due to snakebites & 54 & 0.6 \\
death due to other causes & 3 & $<0.1$ \\
not available & 570 & 6.2 \\
\hline Case classification & & \\
mild & 4,031 & 43.9 \\
moderate & 4,012 & 43.8 \\
severe & 710 & 7.7 \\
not available & 421 & 4.6 \\
\hline
\end{tabular}

in the Amazon exhibit increased activity during months with higher rainfall(20)(21), including Bothrops atrox and Bothriopsis bilineata $^{(22)(23)}$. Moreover, in this period, the snakes look for upland areas during flooding, which increases the likelihood of contact between humans and snakes. A similar seasonal pattern was previously observed in the region, with some microgeographical variations $^{(9)(10)(17)}$.

Table 1 shows the epidemiological characteristics of the 9,174 snakebite cases that were recorded as part of the epidemiological surveillance in Amazonas from 2007-2012. The profile was very similar to that reported in previous publications from the Brazilian Amazon, as seen in the systematic review presented here.

The most affected group was aged 20-39 years (38\%) and of male gender $(78.9 \%)$. Of all incidents recorded in this period, the vast majority occurred in rural areas $(85.6 \%)$. This profile was recorded previously in the Amazon and likely results from the economic activities engaged in by the victims ${ }^{(9)(11)(12)(14)}$. Another important point was that $85.6 \%$ of the bites occurred in the lower limbs. As snakebites in the Amazon are predominantly associated with work in the field, such as forestry and agriculture, the risk of being bitten can be lowered with preventive measures, such as wearing protective footwear and avoiding areas known to be inhabited by dangerous snakes ${ }^{(5)}$.

The predominance of accidents in rural areas is especially troubling to some regions of the Amazon, which presents serious transportation problems for these patients. In some areas, the roads are absent and transportation by rivers to the nearest healthcare facility can take hours or even days. Thus, snakebite victims often use traditional homemade medicines ${ }^{(7)}$, which contributes to the emergence of severe and underreported cases and snakebite-related fatalities. In this regard, the average time until being seen by a health professional was very similar to that reported for other Amazonian regions ${ }^{(11)}$, but it was much higher than in other regions of Brazil(24). However, when compared with a previous case series study in the State of Amazonas (from 1989 to 1996) ${ }^{(9)}$, an improvement in time to patient care was observed. During that period, approximately $56 \%$ of the patients were seen after only 6 hours; however, in the current study, this figure dropped to $29.5 \%$. This pattern might be an important reason for the $1 \%$ to $0.6 \%$ case-fatality reduction that was observed when comparing these two case series.

Bothropic accidents predominated in the present series $(67.3 \%)$, which agrees with studies carried out in other Brazilian Amazon regions ${ }^{(10)(11)(12)}$. Lachetic injuries were responsible for $21.8 \%$ of the snakebites. This value was higher than the national averages, which showed that crotalic accidents were the second most important ${ }^{(5)}$. This fact may be related to the absence of favorable conditions for the development of Crotalus durissus (open fields such as savanna biomes) in the State of Amazonas $^{(17)}$.

\section{DISCUSSION AND FUTURE PERSPECTIVES}

The socioeconomic burden of snakebites is an issue that has been totally neglected in Brazil. In the Brazilian Amazon, no reliable data were available regarding the long-term physical and psychological consequences of surviving snakebites, but as 
most snakebite victims are in the economically productive age group, the economic impact of such disability is likely to be high. Global health resource allocation is often based on disabilityadjusted life-years (DALYs) and other socioeconomic markers rather than on the number of patients and deaths, despite the limitations of each of these measures of burden. Furthermore, there is no information regarding severity, disabilities and casefatality risk factors that are caused by snakebites. Similarly, very little is known about the frequency of secondary infections, the spectrum of bacteria that are responsible for wound infections in snakebite patients, or the susceptibility of these pathogens to antimicrobial agents.

Very little scientifically based information is available regarding snakebite case fatality for many developing countries. In India, verbal autopsy was used to study the fatalities associated with snakebites, which shows that this problem remains an underestimated cause of accidental death in India ${ }^{(25)}$. A verbal autopsy is a method of determining the cause of a death based on an interview with next of kin or other caregivers. In recent years, verbal autopsies have been used more widely to provide information on causes of death in areas where civil registration and death certification systems are weak and where most people die at home without having had contact with the health system. Although Brazil has an active epidemiological surveillance program for envenoming animals, the sensitivity of this program must be determined. Additionally, phylogenetic and venom studies are needed to ensure appropriate design of anti-venoms to cover the species responsible for serious cases of envenomation in the Amazon.

\section{CONCLUSIONS}

In summary, snakebites represent a huge and largely neglected health concern in the Brazilian Amazon. To address this problem, population-based studies of incidence and mortality in countries that appear to have the highest case load and mortality rates are urgently required. Given the high burden, the paucity of reliable snakebite data is both surprising and worrying. Snakebites vary geographically and seasonally and are mainly a rural tropical phenomenon, where reporting and record keeping are poor. In addition, health-seeking behavior is diverse, with traditional medicines sometimes preferred. These factors all contribute to the difficulties faced when studying snakebite epidemiology. The quality of reporting and record keeping in health facilities with regard to morbidity and mortality associated with snakebites should be optimized in the Amazon.

\section{ACKNOWLEDGMENTS}

Thanks to the personnel from the Fundação de Vigilância em Saúde do Estado do Amazonas and from the Department of Epidemiology and Public Health of the Fundação de Medicina Tropical Doutor Heitor Vieira Dourado. We thank Richard Thomson for the English revision of the final version of the manuscript and the reviewers for considerably contributing to the improvement of the manuscript.

\section{CONFLICT OF INTEREST}

The authors declare no conflict of interest during the development of the study.

\section{FINANCIAL SUPPORT}

This work was funded by the Fundação de Medicina Tropical Doutor Heitor Vieira Dourado.

\section{REFERENCES}

1. Chippaux JP. Snakebites: appraisal of the global situation. Bull World Health Organ 1998; 76:515-524.

2. White J. Bites and stings from venomous animals: A global overview. Ther Drug Monit 2000; 22:65-68.

3. Gutierrez JM, Theakston DR, Warrell DA. Confronting the neglected problem of snake bite envenoming: the need for a global partnership. PLoS Med 2006; 3:e150.

4. Kasturiratne A, Wickremasinghe AR, de Silva N, Gunawardena NK, Pathmeswaran A, Premaratna R, et al. The global burden of snakebite: a literature analysis and modelling based on regional estimates of envenoming and deaths. PLoS Med 2008; 5:e218.

5. Ministério da Saúde. Secretaria de Vigilância em Saúde. Acidentes ofídicos. (Internet) (Cited 2013 May 1). Available at: http://portal. saude.gov.br/portal/arquivos/pdf/gve_7ed_web_atual_aap.pdf

6. Gold BS, Dart RC, Barish RA. Bites of venomous snakes. N Engl J Med 2002; 347:347-56.

7. Pierini SV, Warrell DA, de Paulo A, Theakston RD. High incidence of bites and stings by snakes and other animals among rubber tappers and Amazonian Indians of the Juruá Valley, Acre State, Brazil. Toxicon 1996; 34:225-236.

8. Carvalho MA, Nogueira F. Snakes from the urban area of Cuiabá, Mato Grosso: ecological aspects and associated snakebites. Cad Saude Publica 1998; 14:753-763.

9. Campos-Borges C, Sadahiro M, Santos MC. Epidemiological and clinical aspects of snake bites in the municipalities of the state of Amazonas, Brazil. Rev Soc Bras Med Trop 1999; 32:637-646.

10. Nascimento SP. Epidemiological characteristics of snakebites in the State of Roraima, Brazil, 1992-1998. Cad Saude Publica 2000; 16:271-276.

11. Moreno E, Queiroz-Andrade M, Lira-da-Silva RM. Clinical and epidemiological characteristics of snakebites in Rio Branco, Acre. Rev Soc Bras Med Trop 2005; 38:15-21.

12. Lima ACSF, Campos CEC, Ribeiro JR. Epidemiological profile of snake poisoning accidents in the State of Amapá. Rev Soc Bras Med Trop 2009; 42:329-335.

13. Torrez PQ, Duarte MR, França FO, Figueiredo L, Abati P, Campos LR, et al. First report of an accident with the speckled forest pit viper (Bothriopsis taeniata) in Brazil. Rev Soc Bras Med Trop 2009; 42:342-344.

14. Waldez F, Vogt RC. Ecological and epidemiological aspects of snakebites in riversidade communities of the lower Purus River, Amazonas, Brazil. Acta Amaz 2009; 39:681-692.

15. Machado AS, Barbosa FB, Mello GS, Pardal PP. Hemorrhagic stroke related to snakebite by bothrops genus: a case report. Rev Soc Bras Med Trop 2010; 43:602-604. 
16. Pardal PP, Pardal JS, Gadelha MA, Rodrigues LS, Feitosa DT, Prudente AL, et al. Envenomation by Micrurus coral snakes in the Brazilian Amazon region: report of two cases. Rev Inst Med Trop Sao Paulo 2010; 52:333-337.

17. Bernarde PS, Gomes JO. Serpentes peçonhentas e ofidismo em Cruzeiro do Sul, Alto Juruá, Estado do Acre, Brasil. Acta Amaz 2012; 42:65-72.

18. Dourado HV, Burnheim PF, Souza IS, Fonseca-da-Rocha AJ, Santos S. Ofidismo no Amazonas. Poster session presented at: XXIV Congresso da Sociedade Brasileira de Medicina Tropical; 1988. Fev 28-mar 03; Manaus, AM.

19. Burnheim PF, Lima HCL, Oliveira EES. Ocorrência de serpentes peçonhentas na Amazônia e acidentes ofídicos no Amazonas. Poster session presented at: XXIV Congresso da Sociedade Brasileira de Medicina Tropical; 1988. Fev 28-Mar 03; Manaus, AM.

20. Martins M, Oliveira ME. Natural history of snakes in forests of the Manaus region, Central Amazonia, Brazil. Herpetol Nat History 1998; 6:78-150.
21. Bernarde PS, Abe AS. A snake community at Espigão do Oeste, Rondônia, Southwestern Amazon, Brazil. South Am J Herpetol 2006; 1:102-113.

22. Oliveira ME, Martins M. When and where to find a pitviper: activity patterns and habitat use of the lancehead, Bothrops atrox, in central Amazonia, Brazil. Herpetol Nat History 2002; 8:101-110.

23. Turci LCB, Albuquerque S, Bernarde PS, Miranda DB. Activity, habitat use, and behavior of the Bothriopsis bilineatus and of the Bothrops atrox (Serpentes: Viperidae) in Moa river forest, Acre Brazil. Biota Neotrop2009; 9:197-206.

24. Saraiva MG. Perfil epidemiológico dos acidentes ofídicos no Estado da Paraíba, Brasil, 2005 a 2010. Epidemiol Serv Saude 2012; 21: 449-456.

25. Mohapatra B, Warrell DA, Suraweera W, Bhatia P, Dhingra N, Jotkar RM, et al. Snakebite Mortality in India: A Nationally Representative Mortality Survey. PLoS Negl Trop Dis 2011; 5:e1018. 